\title{
Complexidade e inclusão: caminhos, história e tessituras
}

\author{
Maria Dolores Fortes Alves* \\ Adalberto Duarte Pereira Filho**
}

\section{Resumo}

Fala-se de inclusão, cria-se leis, cursos, treinamentos. Cabe-nos dizer que os aspectos legais são necessários e urgentes, todavia, para que sejamos congruentes em discurso e ação é preciso conscientização, mudança de atitude, olhar, percepção. Nesse sentido, vamos buscar respostas para as questões: Inclusão; qual o caminho? Qual minha bússola? Desta feita, caminhos nos remetem a valores: em saber o que importa, quais atitudes e saberes e caminhos. Para tal, nesse artigo, objetivamos dialogar sobre inclusão e complexidade apontando, a partir do olhar moriniano, para o caminho da tessitura comum. O faremos pelo viés qualitativo, em uma senda metodológica teórico reflexiva, tendo como autores de base Morin (2007), Alves (2016) e Moraes (2015) entre outros que nos trazem, mesmo que brevemente, devido ao espaço que nos cabe, fundamentos ontológicos, epistemológicos e metodológicos sobre inclusão, complexidade e Práticas de Aprendizagem Integradoras-PAI. Destarte, percebemos ao final que atitudes se materializam quando há o desejo de conexão, quando no outro e em nós há o sentimento de pertença, de ligação, de interdendência. Assim, filosoficamente falando, não há vazio que não se

* Professora de graduação e pós graduação da Universidade Federal de Alagoas-UFAL CEDU PPGE; Doutora e Mestre em Educação:Curriculo PUC/SP-CNPq e UB (Barcelona); Mestre em Psicopedagogia e Pedagoga - UNISA; líder do Grupo de Pesquisa PAII (Praticas e Aprendizagens Integradoras e Inovadoras), Pesquisadora RIES (Rede Internacional Ecologia dos Saberes), ECOTRANSD (Ecologia dos Saberes e Transdisciplinaridade - CNPq), RIEC (Rede Internacional de Escolas Criativas), GIAD (Grupo de Investigação e Assessoramento Didático. UB) e ADESTE (A Adversidade Esconde um Tesouro - Universidade de Barcelona); E-mail: mdfortes@ gmail.com.

** Doutorando e mestre pelo programa de pós-graduação em educação da Universidade Federal de Alagoas - PPGE/UFAL.adalberto-duarte@hotmail.com 
preencha quando encontramos o sentido de nossa existência, junto com o "outro". O outro que se faz nosso espelho e complementar, nossa outra parte, nosso holograma.

Palavras-chave: inclusão, complexidade, Práticas de aprendizagem integradoras

\section{Complexity and including: paths, history and tes- situres}

\section{Abstract}

We talk about inclusion, we create laws, courses, trainings. It is up to us to say that the legal aspects are necessary and urgent, however, in order to be congruent in speech and action it is necessary to be aware, change of attitude, look, perception. In this sense, we will seek answers to the questions: Inclusion; what is the way? What is my compass? This time, paths lead us to values: in knowing what matters, what attitudes and knowledge and paths. To this end, in this article, we aim to talk about inclusion and complexity, pointing, from the Morinian perspective, to the path of common texture. We will do so by the qualitative bias, in a reflective theoretical methodological path, having as base authors Morin (2007), Alves (2016) and Moraes (2015) among others that bring us, even if briefly, due to the space that is ours, ontological, epistemological and methodological foundations on inclusion, complexity and Learning Practices Integrators PAI. Thus, we realize at the end that attitudes materialize when there is the desire for connection, when in the other and in us there is the feeling of belonging, connection, interdendence. Thus, philosophically speaking, there is no emptiness that is not filled when we find the sense of our existence, together with the "other". The other becomes our mirror and complement, our other part, our hologram.

Keywords: inclusion, complexity, practices integrative learning

\section{Complejidad y inclusión: senderos, historia y tesituras}

\section{Resumen}

Hablamos de inclusión, creamos leyes, cursos, formación. Debemos decir que los aspectos legales son necesarios y urgentes, sin embargo, para ser congruentes en el discurso y la acción es necesaria la conciencia, el cambio de actitud, la mirada, la percepción. En este sentido, buscaremos respuestas 
a las preguntas: Inclusión; ¿cuál es el camino? ¿Qué es mi brújula? Esta vez, los caminos nos llevan a los valores: en saber qué es lo que importa, qué actitudes y conocimientos y caminos. Para ello, en este artículo, pretendemos dialogar sobre la inclusión y la complejidad, señalando, desde la perspectiva moriniana, el camino de la tesitura común. Lo haremos a través de un sesgo cualitativo, en un camino metodológico teórico reflexivo, teniendo como base a los autores Morin (2007), Alves (2016) y Moraes (2015) entre otros que nos traen, aunque sea brevemente, por el espacio que nos cabe, fundamentos ontológicos, epistemológicos y metodológicos sobre inclusión, complejidad y Prácticas Integradas de Aprendizaje-PAI. Por lo tanto, al final nos damos cuenta de que las actitudes se materializan cuando existe el deseo de conexión, cuando en el otro y en nosotros existe el sentimiento de pertenencia, conexión, interdependencia. Por lo tanto, filosóficamente hablando, no hay ningún vacío que no pueda ser llenado cuando descubrimos el sentido de nuestra existencia, junto con el "otro". El otro que se hace nuestro espejo y complemento, nuestra otra parte, nuestro holograma.

Palabras clave: inclusión, complejidad, prácticas de aprendizaje integradoras

\section{Introdução}

Cada vez mais e necessariamente criamos projetos, políticas, leis, tecnologias, cursos, treinamentos sobre inclusão. Sabemos que todos esses dispositivos são importantes, necessários e urgentes no processo inclusivo. Entretanto, para que haja congruência entre o discurso e a ação de incluir, é preciso que haja a elevação das consciências. Para tanto, buscaremos respostas para algumas questões: Inclusão; o que me conduz ao caminho? Quais são nossos nortes para sua efetivação? Logo, este artigo teórico, objetiva dialogar sobre o pensar complexo e a inclusão apontando possíveis caminhos para uma tessitura comum, para a construção da congruência entre discurso e ação, da construção histórica do que é inclusão e possibilidades de "lugares" e pertencimentos de sujeitos singulares. O faremos pelo viés qualitativo, em uma senda metodólogica teórico reflexivo tendo como autores de base Morin (2007), Alves (2016) e Moraes (2015) entre outros que nos trazem, mesmo que brevemente, devido ao espaço que nos cabe, fundamentos ontológicos, epistemológicos e metodológicos sobre complexidade, inclusão e práticas de aprendizagem integradoras e inclusivas. 


\section{Complexidade: o tecido que se faz pelos diversos fios}

Para Freire "ninguém caminha sem aprender a caminhar, sem aprender a fazer o caminho caminhando, refazendo e retocando o sonho pelo qual se pôs a caminhar" (2018, p. 155). Assim se faz a inclusão. Um caminho que se faz caminhando, convivendo ressignificando cada nova, supernova experiência. O caminho é o caminho que se faz caminhando e cantando e seguindo a canção, a canção da vida. O caminho é a empatía, significação, tessitura, interrelacão, interdependência, colaboração, codependencia, cocriação, coracão. co-operação, com-paixão. A teoria da complexidade de Edgar Morin, propõe o pensamento que integra, em lugar do pensamento que fragmenta e separa. O pensamento complexo é "essencialmente um pensamento que trata com a incerteza e que é capaz de conhecer a organização. É o pensamento apto a reunir, contextualizar, globalizar, mas ao mesmo tempo reconhecer o singular, o individual, o concreto" (MORIN, 2000, p. 213). Tece, "como numa tapeçaria de vários fios, as relações entre os múltiplos tipos de pensamentos” (PETRAGLIA, 2008, p. 17).

É visível, a grandiosa colaboração deste pensamento para a educação. Sob este entendimento, podemos observar a escola como um acontecimento complexo, que ao acolher grande diversidade de culturas, pensamentos e sentimentos se torna um ambiente propício para a reforma do pensamento. É necessário "repensar a reforma e reformar o pensamento" (MORIN, 2015, p. 22), tendo em vista que, não adianta apenas ensinar enchendo a cabeça dos educandos de conteúdos disciplinares, de modo desconectado, é necessário dar significados os conhecimentos que chegam a eles. É importante gerar o pensar complexo, pois é este que proporcionará a contextualização da formação crítica dos aprendizes (MORIN, 2007).

Certamente, o pensamento complexo é uma das formas mais coerentes para perceber os desafios da atualidade, notadamente no que diz respeito às escolas e seus atores diários. Este exemplo é dado, ao perceber que ainda são necessárias mais dis- 
cussões sobre humanização e um olhar ecológico de pertencimento, dentro dos muros das escolas. Pois, enquanto isto não for uma discussão efetiva, viveremos em constante fragmentação do ser. A complexidade, quando entendida no viés de Morin, está ligada a busca de boas práticas pedagógicas, aquelas que visem a religação do ser, aquela que reúnem e compreendem as partes. Neste entendimento,

a complexidade é um tecido (complexus: o que é tecido junto) de constituintes heterogêneas inseparavelmente associadas: ela coloca o paradoxo do uno e do múltiplo. Num segundo momento, a complexidade é efetivamente o tecido de acontecimentos, ações, interações, retroações, determinações, acasos, que constituem nosso mundo fenomênico (MORIN, 2005, p. 13).

Compreendemos desta forma, o pensamento complexo como "o que é tecido junto". Tudo que parte do todo, mas também do indivíduo, porém, podendo criar conexões, relações, e desta forma, religar saberes e caminhos.

Autores como Gaston Bachelard e Warren Weaver, ao longo da modernidade, propuseram a iniciativa da criação de um pensamento complexo na produção do conhecimento (MORIN, 2005). No entanto, tal proposta nunca foi tão forte quanto nas obras e proposições de Edgar Morin. Para esse pensador, o entrelaçado cooperativo de conhecimentos nega a simplificação e propõe uma relação dialógica a partir dos operadores cognitivos do pensamento complexo, que buscam religar complexamente a ciência fragmentada. Para Morin (2015, p. 175) “a problemática da complexidade ainda é marginal no pensamento científico, no pensamento epistemológico e no pensamento filosófico". Tais proposições ainda não chegaram a se consolidar nos meios de produção de conhecimento, ao menos, não de forma hegemônica, isso porque a complexidade nos convoca a uma "reforma do pensamento" (idem). Isso implicaria uma nova abordagem e compreensão de um mundo que complexamente se autoproduz. 
Assim, a partir da proposta de religar o conhecimento, Morin (2017) convoca a uma reforma do pensamento. Ele aponta que é necessário religar, integrar o conhecimento, isso implica ultrapassar a confusão, o embaraço e a dificuldade de pensar organizadamente, efetuando conexões e distinções. Para essa reforma do pensamento se instituir não cabe apenas pensá-la "no nível da universidade, mas desde o ensino fundamental" (idem, p. 120). O ponto nevrálgico é a educação dos educadores. Para Morin (2015) o ponto de partida deve ser a autoeducação com o auxílio dos educandos. A proposição de Morin (2007) é que a educação seja horizontal, autônoma, com trocas e articulação dos conhecimentos dos sujeitos que aprendem mutuamente mediatizados pelo mundo e pelas relações (FREIRE, 2018).

Faz-se fundamental pensar na visão de homem e mundo dentro do pensamento complexo, para buscar investigar qual a relação que o pensamento complexo estabelece com a ciência experimental, metodologia hegemônica no fazer científico moderno. Para Morin (2003), enquanto a cultura geral comportava a possibilidade de buscar a contextualização de toda informação ou ideia, a cultura científica e técnica, por causa de sua característica disciplinar e especializada, separa e compartimenta os saberes, tornando cada vez mais difícil a colocação destes num contexto qualquer. Então, na busca por alternativas que resolvam ou que rompam com essa prática especializada que limita cada vez mais os saberes, é que se faz necessária a compreensão do pensamento complexo, defendido e descrito por Morin (2015). A complexidade, se lança como um desafio de superar as condições limitadoras que o pensamento reducionista impôs sobre a produção do conhecimento. Ao defender a busca por um conhecimento que considere as várias dimensões que estão presentes num fenômeno estudado, a complexidade causa o mal-entendido de que propõe o conhecimento completo e certo. Morin (2005, p. 176) esclarece este mal-entendido ao afirmar o seguinte:

O problema da complexidade não é o da completude, mas o da incompletude do conhecimento. Num sentido, o pensamento complexo tenta 
dar conta daquilo que os tipos de pensamento mutilante se desfazem, excluindo o que eu chamo de simplificadores e por isso ele luta, não contra a incompletude, mas contra a mutilação.

Assim, a complexidade surge da necessidade de ir além das certezas, dos determinismos, das mutilações, da simplificação dos fenômenos como um todo, considerando todas as dimensões envolvidas no fenômeno estudado. Como descreve Morin (2005, p.177) "ela não quer dar todas as informações sobre um fenômeno estudado, mas respeitar suas diversas dimensões".

Para aprofundar na descrição da complexidade é necessária a compreensão da visão de mundo, ou melhor, da visão de universo que esta possui, e que é neste universo que estão inseridos todos os fenômenos a serem estudados. Portanto, ao se estudar um fenômeno, deve-se atentar para o contexto onde este está inserido. Nesse sentido, Morin (2003, p. 14) afirma o seguinte:

Todos os problemas se situam em um nível global e, por isso, devemos mobilizar a nossa atitude não só para os contextualizar, mas ainda para os mundializar, para os globalizar; devemos, em seguida, partir do global para o particular e do particular para o global, que é o sentido da frase de Pascal: "Não posso conhecer o todo se não conhecer particularmente as partes, e não posso conhecer as partes se não conhecer o todo”.

Mas essa necessidade não surge apenas nos dias de hoje, o fenômeno da globalização apenas evidencia essa necessidade para a abordagem da complexidade. O problema da separação, da simplificação, e que compartimenta os fenômenos e objetos estudados no processo de produção do conhecimento, está presente no método científico experimental, ou seja, na ciência moderna. Segundo Morin (2003, p. 14), "o método experimental, que permite tirar um 'corpo' do seu meio natural e colocá-lo num meio artificial, é útil, mas tem os seus limites, pois não podemos estar separados do nosso meio ambiente". O problema dessa separação, compartimento e simplificação estaria no fato de os fenômenos, os objetos e o próprio ser humano estarem numa realidade multidimensional. Como esclarece Morin (2003, p. 14): 
Vivemos numa realidade multidimensional, simultaneamente econômica, psicológica, mitológica, sociológica, mas estudamos estas dimensões separadamente, e não umas em relação com as outras. O princípio de separação torna-nos talvez mais lúcidos sobre uma pequena parte separada do seu contexto, mas nos torna cegos ou míopes sobre a relação entre a parte e o seu contexto.

Para descrever e tentar guiar o pensamento complexo, Morin (2003) estabeleceu alguns princípios, complementares e interdependentes, os mesmos ajudam na compreensão da complexidade. Esses princípios são conhecidos como operadores cognitivos, sendo eles: o princípio ético, ecologia da ação, enação, princípio sistêmico ou organizacional, hologramático, anel retroativo, recursivo, auto-eco-organizativo, dialógico e o princípio da reintrodução.

De acordo com Morin (2002) o princípio ético contempla os valores éticos do sujeito complexo, esses valores podem reverberar em atitudes com responsabilização frente ao outro, a humanidade, ao ecossistema, a todos os elementos inter-relacionados no mundo. Tais atitudes, fundadas na ética, tendem a se ecologizar, gerando outras ações positivas no mundo. O princípio da ecologia das ações afirma que toda ação realizada se ecologiza, influenciando outros fenômenos, que também se ecologizam e assim, sucessivamente, influenciando todo o cosmo. Outro princípio fundamental para se compreender a complexidade é o da enação, no qual o sujeito e o mundo estão coimbricados, a percepção e ação são inseparáveis, o sujeito e o objeto integram a integralidade.

Seguindo na tentativa de compreender os caminhos para se pensar a complexidade, a ideia sistêmica, que é oposta a ideia reducionista, acredita que o todo é mais do que as soma das partes. Isso revela sobre o princípio organizacional ou sistêmico, que liga o conhecimento das partes ao conhecimento do todo, sendo, portanto, impossível compreender o todo sem conhecer suas partes e vice-versa. O princípio sistêmico está em considerar o todo ao estudar as partes, e considerar as partes ao estudar o todo (MORIN, 2005). Como descreve Morin (2003) a organização do ser vivo gera 
qualidades desconhecidas de seus componentes físico-químicos. É válido ressaltar que o princípio sistêmico/organizacional tem uma ligação com o próximo, sendo este o hologramático (MORIN, 2002) e portanto, compreendê-lo faz-se necessário para observar as semelhanças existentes.

É possível entender um holograma como uma projeção que forma uma figura, um todo, e neste todo existem inúmeras partes, que cada umas delas contém quase uma totalidade da informação do objeto representado. Nesse sentido, não apenas o todo carrega as partes, mas também as partes carregam quase o todo por completo, como em um holograma, onde as diferentes fontes de formação do mesmo, possuem quase todas as suas características finais.

Outros dois princípios são o do anel retroativo e o do anel recursivo. $\mathrm{O}$ anel retroativo parte do princípio de que a causa age sobre o efeito e o efeito sobre a causa, proporcionando assim uma autorregulação, um equilíbrio, que contribui com a autonomia do sistema, evitando desvios que possam prejudicar o funcionamento do mesmo (MORIN, 2003). Este princípio, diz respeito a autoregulação do ser. O conjunto de processos reguladores, fundados sobre múltiplas retroações, propiciam o equilíbrio de um organismo vivo e isso gera uma homeostase. Já o princípio do anel recursivo, embora também contribua para a autonomia do sistema, se difere do princípio anterior, conserva a característica de causa e efeito, mas nesse caso essa característica está pautada na interdependência dos múltiplos fatores envolvidos num fenômeno ou produto, onde "os produtos e os efeitos são produtores e causadores do que produz" (MORIN, 2003, p. 15). Morin (2005, p. 182) exemplifica o anel recursivo através de uma sociedade enquanto sistema:

Uma sociedade é produzida pelas interações entre indivíduos e essas interações produzem um todo organizador que retroage sobre os indivíduos para coproduzi-los enquanto indivíduos humanos, o que eles não seriam se não dispusessem da instrução, da linguagem e da cultura. 
Sendo assim, nós, seres humanos somos produtores do meio que nós mesmos produzimos, somos causadores do que o meio nos causa (MORIN, 2002).

Um outro princípio é o de autonomia/dependência, ou de auto-eco-organização, e já foi mencionado nas descrições dos princípios anteriores. Esse princípio, parte do fato de que os indivíduos dependem do meio em que estão envoltos para que continuem a manter a sua autonomia. Segundo Morin (2005, p. 184) "a autonomia se fundamenta na dependência do meio ambiente e o conceito de autonomia passa a ser um conceito complementar ao da dependência, embora lhe seja, também, antagônico".

Como afirma Morin (2003), o princípio de auto-eco-organização vale evidentemente de maneira específica para os humanos, que desenvolvem a sua autonomia na dependência da cultura, e para as sociedades que dependem do meio geoecológico. Diante o exposto, é possível perceber que, na medida em que o ser humano é um ser autônomo ele também é dependente. Existe uma ligação da autonomia do sujeito com a dependência no meio em que ele vive. O ser tem a autonomia de fazer diversas coisas no mundo, porém para essa execução ele necessita do meio em que vive, do mundo, do ecossistema e dessa forma ele se auto-eco-organiza.

Com relação ao princípio dialógico, compreende-se que as noções contraditórias devem ser associadas para conceber um mesmo fenômeno complexo. Sendo assim, propõe a união de princípios que são indissociáveis numa mesma realidade, não devendo, portanto, excluir nem um nem o outro. A aplicação da dialogicidade na educação, na constituição dos sujeitos que frequentam as instituições escolares é de fundamental importância para fazer perceber o quanto as divergências de cultura, modos de vestir, ser, de conhecer, aprender e se posicionar diante da vida e dos acontecimentos, tanto dos alunos quanto dos professores, fomenta interrogações e mais interrogações, permitindo manter sempre em movimento a construção dos saberes que perpassam a todos. 
Em continuidade, observa-se o princípio que propõe o retorno do sujeito observador a sua observação, no processo de produção do conhecimento. Esse é o princípio da reintrodução do sujeito cognoscente. (MORIN, 2005). Tal princípio aborda o sujeito construtor do conhecimento. Assim, todo o conhecimento é uma tradução de um espírito/cérebro que está inserido em uma determinada cultura, com seus costumes, modos de ser e portanto, revela aspectos que estão inseridos neste contexto.

Diante do exposto, é válido salientar que o princípio dialógico, recursivo e hologramático são o tripé da complexidade. Esses são alguns dos princípios estabelecidos por Morin (2003) para compreender e guiar o pensamento complexo, no entanto, esse pensamento não pretende substituir ou combater o pensamento até então existente, pelo contrário, pretende complementá-lo.

O que fica evidente é que o pensamento complexo na compreensão de Morin se pretende apenas a resolver o que poderia ser considerado como faltas deixadas pelo pensamento científico hegemônico. Em outras palavras, a proposta de um pensamento complexo na produção de conhecimento estaria mais preocupada em reformar o modelo científico atual, do que propriamente romper com esse modelo. É possível, também, concluir que a complexidade defende uma maior atenção as múltiplas dimensões de um fenômeno, muitas vezes negligenciadas pelas formas de produção de conhecimentos atuais. Atribui muita importância as interrelações estabelecidas pelos fenômenos, defende a necessidade de atentar-se a essas, ao considerar que é importante que se compreenda também as partes ao estudar o todo, que se compreenda também o todo ao estudar as partes. Construir uma nova perspectiva de educação é um desafio que se anuncia, na busca de concepções inclusivas e inovadoras de fazer a escola. Acerca dessas concepções, discutiremos mais detalhadamente a seguir.

\section{Inclusão: Caminhos e história}

O desenvolver da história tem, ao longo do tempo, apontado a necessidade urgente da construção de uma escola inclusiva. Segundo Amaral et al. (2014, p. 3), "historicamente, a existência 
discriminatória da escola e de toda sociedade limita-se à escolarização de um grupo seleto e homogêneo". Esse quadro, no Brasil, só foi frontalmente questionado a partir da publicação do manifesto dos pioneiros da Educação Nova em 1932 que trazia em seu bojo a reivindicação de uma escola obrigatória e para todos (TEIXEIRA et al. 2010). Sob a inspiração do escolanovismo foi promulgada a $1^{\mathrm{a}}$ Lei de Diretrizes e Bases da Educação Nacional no Brasil (LDB), Lei $n^{\circ} 4.024$ de 1961 (BRASIL, 1961), que garantia o direito à educação a todos em escolas regulares e incluía nesse conjunto as crianças com necessidades educacionais especiais.

A partir do golpe militar de 1964 passou a ser implementado um conjunto de reformas educacionais que traziam em seu bojo a necessidade de assegurar o domínio das ideias e das ações dos brasileiros. Dentre as reformas empreendidas é aceitável aludir a Lei $\mathrm{n}^{\circ}$ 5.692 de 1971 (BRASIL, 1971) que reformou os ensinos de $1^{\circ}$ e $2^{\circ}$ graus que segregou os educandos com necessidades educacionais especiais em salas específicas, apartadas da escola regular, reforçando assim a lógica da exclusão.

Mais adiante, com a queda do regime militar na década de 1980, retomou-se a discussão democrática acerca da educação inclusiva. A Constituição Federal de 1988 estabeleceu no Art. 30 ${ }^{\circ}$ inciso V, Imbuída de um espírito democrático afirma que é objetivo fundamental da União, dos Estados, do Distrito Federal e dos Municípios "promover o bem de todos, sem preconceitos de origem, raça, sexo, cor, idade e quaisquer outras formas de discriminação" (BRASIL, 1988). A CF de 1988 determinou uma nova Lei de Diretrizes e Bases que foi promulgada no formato da Lei ${ }^{\circ} 9.394$ de 1996. Nesta está reservado um capítulo completo sobre Educação Especial (Título V, Capítulo V). Precisioso explicitar que a LDB de 1996 propõe também diretrizes sobre a Educação de Jovens e Adultos, da Educação a Distância, da Educação para as relações étnico racionais, Educação para os Direitos Humanos. No percurso de sua escrita verificamos a preocupação do legislador em direcionar a educação brasileira em direção a um movimento inclusivo. 
Desdobrando-se da LDB9394/96 supracitada, instituí-se em 2001 a Lei no 10.172, de 9 de janeiro de 2001 que ratificou o Plano Nacional de Educação (PNE) com vigência de dez anos (20012010). Tal documento expoe sobre a educação inclusiva se conclui que "o grande avanço que a década da educação deveria produzir seria a construção de uma escola inclusiva” (BRASIL, 2001). O Plano Nacional de Educação, aprovado em 2014, com vigência até 2024, no formato da Lei no 13.005, de 25 de junho de 2014 (BRASIL, 2014), robustece o imperativo de se edificar não apenas uma escola, mas também, uma universidade e uma sociedade inclusivas.

Desta feita, o percurso brasileiro acerca da Educação Inclusiva discorre historicamente com movimentos internacionais que problematizaram a Educação Especial, como tal, a Declaração Mundial de Educação para Todos (1998) e a Declaração de Salamanca (1994). Em diálogo com organismos internacionais, a exemplo da UNESCO, a Secretaria de Direitos Humanos, os Ministérios da Educação e da Justiça brasileiros organizaram em 2006 o Plano Nacional de Educação em Direitos Humanos. Tal relatório, “incorpora aspectos dos principais documentos internacionais de direitos humanos dos quais o Brasil é signatário, agregando demandas antigas e contemporâneas de nossa sociedade" (BRASIL, 2007, p. 11).

Atualmente, no campo da formação de professores, foram instituídos componentes curriculares obrigatórios que dispoem-se a provocar uma reflexão sobre a mister inclusão dos sujeitos na escola, na universidade e na sociedade (BRASIL, 2015). Conforme Baptista (2005, p. 16), o debate sobre a educação inclusiva "tem exigido que a discussão teórica em pedagogia ultrapasse os muros disciplinares específicos". Para Guijaro (2005, p. 9), a educação inclusiva deve se basear "na heterogeneidade e não na homogeneidade, considerando que cada aluno tem uma capacidade, interesse, motivações e experiência pessoal única".

A inclusão escolar em seu percurso histórico foi compreendida restritamente à inserção de pessoas com deficiência que outrora estavam em salas de escolas especiais e em escolas regulares. Esta 
concepção reducionista de algum modo se sustenta na contemporaneidade. No movimento pela inclusão seguimos a construção de um entendimento ampliado do processo de inclusão que procura assegurar o direito a uma educação para todos, como nos afirma Mantoan (2013): garantir o direito à diferença na igualdade de direitos à educação.

A educação é um direito incondicional e intransponível assegurado pela constituição de 1988 e fundamentado pela Convenção internacional dos direitos da pessoa com deficiência. A inserção na escola é indiscutivelmente necessária ainda que por artificio da seguridade legal, mas isso por si só não é suficiente para efetivar a inclusão em todo sistema escolar. A efetivação da inclusão é assegurar o direito a diferença propiciando a participação nos âmbitos da escola e da sociedade respeitando a individualidade de cada sujeito, é assegurar a igualdade na diferença.

Não há inclusão por meio da construção de uma identidade para todos, de um molde que massifica a unidade do sujeito e o unifica por uma semelhança qualquer, ou por uma arbitrariedade binária como ser normal ou especial, bom ou mal. A inclusão assegura o direito a diferença onde mesmo que, por estarem marcados por uma semelhança, continuam sendo diferentes entre si. Para Mantoan (2013) em torno das práticas de inclusão há duas questões de fundo: a produção da identidade e da diferença. A inclusão instabiliza a identidade, que é compreendida como característica imutável e fixa que unifica uma comunidade e que nesse contexto questiona a diferença.

Entendemos que a identidade enquanto forma de unificar é uma armadilha, a inclusão se institui no reconhecimento da diferença em processos educacionais iguais, um traço comum não define os sujeitos numa unidade. Como afirma Santos (2013) temos o direito de ser iguais quando a nossa diferença nos inferioriza e temos o direito de sermos diferentes quando a igualdade nos trivializa. $\mathrm{Na}$ prática pedagógica precisamos estar atentos para não recair em diferenciações que excluem e nem pender para igualdade que descaracteriza o sujeito. 
A diferença privilegia sujeitos únicos, singulares, que não atendem a lógica da identidade que classifica e exclui, notoriza.se quando se separam alunos adiantados em uma sala e os atrasados em outra. Somos claramente demandados, no âmbito das relações, a transformar sujeitos complexos em sujeitos simplistas, pondo-os em moldes disciplinares excludentes em nome de uma padronização hegemônica que não atende as formas da infância da contemporaneidade. Os caracteres que fazem os sujeitos diferente são abstraídos em nome de uma universalização. Neste território nefasto a inclusão perde seu sentido, já que os sujeitos são concebidos igualmente e assim são abolidos de suas especificidades. A questão central da inclusão é que não se abstrai a diferença em nome da universalização.

Garantir o processo de inclusão é reagir contra os valores hegemônicos da sociedade dominante e rejeitar o pluralismo, que se sustenta pela mera aceitação do outro, sem conflito e sem confronto. Entendemos ser impossível essa aceitação já que o processo de inclusão desestabiliza a diferença tolerada e questiona os valores sociais marginalizantes. De forma prática, podemos exemplificar que a inclusão acontece para além da arquitetura e da ausência de incomodo daqueles que se preservam em suas zonas de conforto normalizantes. Acontece quando um aluno cadeirante exerce o direito de optar por onde deseja sentar na sala de aula, burlando normatizações mascaradas de atitude pedagógica que obriga a se sujeitar a sentar à frente de todos, todavia seus colegas, por quem nutre laços de amizade, sentam ao fundo da sala. Esse exemplo se aplica a qualquer situação de inclusão, seja com aluno cego ou com baixa visão que opta por usar computador ou sistema braile na sala de aula. Também, por crianças institucionalizadas que preferem manter suas histórias de vida silenciadas no ambiente escolar, mesmo que que estas situações sejam evocadas sustentados em aspectos do preconceito mascarados pela curiosidade. Sabemos que essas histórias são fartas de significados e significantes de sofrimento, abandono, ódio, violação do corpo, da alma e do social. Para que uma pedagogia da inclusão aconteça na escola ela deverá acolher a 
diferença reconhecendo a condição múltipla do humano. Essa condição é singular, não se repete em outros sujeitos. $\mathrm{O}$ acolhimento à diferença é um imperativo da escola inclusiva. Para Alves, "a inclusão verdadeira se faz na aceitação do outro como legítimo outro, bem como na aceitação de si mesmo como legítimo único, singular, fio da teia da vida, interligado a tudo e a todos". (2016, p.39) .

\section{Práticas de Aprendizagem Integradoras e Inclusi- vas: caminhos possíveis para tessitura}

Pensar em direitos iguais, não implica pensar em sujeitos iguais. A igualdade da lei dispõe a todos o acesso ao objeto que o direito assegura, mas o usofruto cada um goza a seu modo pela via da subjetividade e da singularidade.

Diante desse cenário, faz-se necessário pensar a escola como um lugar de elevação das consciências, onde pela via de práticas de aprendizagem integradora e inclusivas ${ }^{1}$ um mecanismo capaz de alavancar esse sistema subterrado pelos nefastos efeitos e de (re) produção da exclusão, se estabeleça. As práticas de aprendizagem integradoras e inclusivas (PAII) são ações que visam desenvolver a consciência da condição humana pela via da educação (ALVES, 2016). Nesse contexto a educação é pensada para além dos processos cognitivos, como ferramenta de compreensão do outro em sua condição singular, frente a complexidade do humano.

Considerar que o humano se constitui como tal, frente ao campo relacional com o outro, faz das PAII instrumentos de intervenção e prática que se instituem ao valorizar, no contexto escolar, os afetos, a superação de si, a construção relacional como outro, a aceitação da diferença e da singularidade. Pensar a inclusão e as PAII é possibilitar a criação de estratégias de convivência humana,

A palavra integradora não configura nenhuma forma de comungar com os equívocos da integração/segregação que assolaram historicamente o processo inclusivo. É consonante com o pensamento de Alves (2016) que a define como ações que visam desenvolver a consciência da condição humana pela via da educação fundamentada no pensamento complexo, na transdisciplinaridade e na ecoformação. 
sustentada pelo aparato da afetividade, da comunicação e da legitimação do outro como legítimo outro.

Essas práticas de aprendizagem integradoras e inclusivas, são o produto da tese de doutoramento de Alves (2016), que a partir de sua posição sobre suas limitações físicas enquanto pessoa com deficiência, desenvolve formas que unem a percepção, a ação, a intução, a cognição e a afetividade para posicionar-se no mundo. As PAII, são possibilidades interventivas em educação que nos viabilizam dar sentido e significado as coisas que fazemos, aprendemos, reinventando e criando novos modos de viver-aprender-fazer e conviver frente aos obstáculos. Isso implica uma posição subjetiva, um modus particular de recriar-se, de conviver, de interser.

As PAII, são fundamentadas no pensamento complexo (MORIN,2015), transdisciplinar (NICOLESCU,2009) e ecossistêmico (MORAES, 2015) e atuam como uma maneira de identificar e potencializar o processo criativo e de autoria dos sujeitos. Tais práticas outorgam a materialização de sujeitos autênticos, autores de si mesmos, apropriados de suas histórias, superações e (re)invenções da vida cotidiana. Esses sujeitos, dotados de seus corpos unitariamente subjetivados e pulsantes, reconhecem que a vida acontece no aqui e agora.

As PAIIs embebidas da complexidade rompem com o pensamento dual de bem/mal, bonito/feio, homem/mulher, normal/ anormal, certo/errado (ALVES, 2016). O objetivo das PAII é o desenvolvimento humano nas diversas dimensões do ser triúnico (O ser consigo, com o outro e com o todo, individuo/espécie/sociedade), e nos diversos espaços como escolas, comunidades, empresas e contextos. Tal modo, que o produto final seja a promoção da consciência da condição humana em sua inteireza e interdependència.

A condição humana é constituída em um ciclo recursivo onde o homem, a natureza e a sociedade funcionam interdependentemente como um corpo triúnico, assim, se um elemento desse circuito adoece, o conjunto inteiro é afeitado. O contrário também é verdade, somos produto e produtores de nós mesmo (ALVES, 
2016). Pensar os caminhos da inclusão e a inclusão como caminho (ALVES; MURADAS, 2015; ALVES; PEREIRA FILHO, 2018; ALVES; SOARES, 2018) exige pensar a posição do homem enquanto sujeito de relação ternária.

Igualmente, compreendemos que o pensamento fragmentado, sustentado pela lógica clássica (NICOLESCU, 2002), limita esse pensar amplificado. Decartes (1970) sugere o pensamento, como uma estrutura proposicional e o divide em gêneros. Assim desde Descartes o homem aprendeu a dividir. O homem em seu domínio racional, mestre da natureza, apropria-se de tudo e de todos numa relação em cadeia de subjugação dos homens e do mundo. O senhorio humano produz categorizações que perpassam pela religião, pela economia e até mesmo pela educação, a dimensão humana é reduzida a um corpo sem corporeidade, um corpo organismo, apenas carne.

A educação segue apoiada nessa lógica homem-pensante, que consiste, numa "razão doentia, patologizante, da eficácia pela eficácia, propagadora da racionalização instrumental a serviço dos delírios e das crueldades humanas" (ALVES, 2016 p. 34). Todavia cabe-nos, a partir de Morin (2015), religar o pensamento e o conhecimento complexamente, já que a contextura social da nossa época considera uma educação para a era relacional. Assim, Morin (2015) pressupõe o alcance de um novo patamar na história da evolução da humanidade no sentido de corrigir os inúmeros desequilíbrios existentes.

A partir da lógica de um pensamento patologizante e do cenário atual da educação, parece que no contexto da inclusão escolar tudo que se refere ao humano, precisa ter plena funcionalidade tal como máquinas com engrenagens que devem funcionar ao pressionar o botão ou controle remoto, ou ao controle de voz. São sujeitos que precisam atender aos manuais de instruções. Nessa lógica, as peças que não funcionarem devem ser substituídas, tudo que não se encaixar deve ser excomungado (ALVES; MURADA, 2015).

A possibilidade de uma convivência na diferença é atrapalhada por essa contextura e as pessoas com deficiência não atendem a esses manuais. Essas deficiências aqui expostas configuram mais 
que questões físicas, mas englobam também questões sociais: crianças pobres, negras, homossexuais, transexuais, são muitas as exigências massificadoras produzidas pelo homem e por sua tirania mortífera, a ausência identitária de si no mundo. O desconhecimento de si, produz a estranheza no outro, aquilo que Freud (1919/1996, p. 235) afirma que o "o estranho, unheimlich, é de alguma forma familiar". Para Alves (2016, p. 35), "as pessoas passam a ter medo das diferenças, medo das mudanças do não conhecido porque desconhecem em si mesmo, suas possibilidades, cegas diante de tantos limites". Assim, receio sobre a diferença é o reconhecimento do avesso, da apropriação com a identificação do próprio terror em ser humano.

As formas biográficas de viver incidentes no individualismo, no enclausuramento, na anulação do outro, como forma possível de garantir a própria segurança em relação ao outro. Esses modos de viver impossibilitam o convívio com e em diversidade, a vida em cooperação, as identificações, partilhas e aprendizagens, não atendem a multidimensionalidade humana.

A cultura reducionista da fragmentação presente na cultura escolar impede o favorecimento da inclusão. As subjetividades e intersubjetividades são substituídas pela objetividade de um cientificismo pragmático, repartido, seccionado. Não há dialogicidade entre as dimensões humanas, entre níveis de realidade que complexificam o homem/mulher.

Segundo Alves (2016) a dimensão social não era reconhecida nesse contexto como um elemento a ser integrado ao ser e ao viver. Esses moldes de produzir pessoas ainda estão em voga nas escolas, nessa forma uníssona, só cabe o ensino fragmentado desarticulado com a multimenssionalidade humana, é um artificio de objetividade falsa. A educação é reduzida ao conteúdo e desarticulado da vida, da realidade e do contexto social, não se faz libertária, autônoma, complexa, transdisciplinar. Arriscamos dizer que a escola produz sujeitos deficientes de afeto, de tolerância, a sensibilidade, a escola que deseja suprimir a diferença. É construída no modelo dual 
para ser asséptica, plena de perfeições e certezas higienistas (ALVES, 2016). A aprendizagem não ocorre de maneira ativa, nesse paradigma está pronta, impossibilitada de colocar o aluno numa posição criativa do processo. É proibido expor as próprias ideias sentimentos e necessidades, a capacidade de construir, argumentar e defender sua argumentação.

Os efeitos desse paradigma acionam a escola e a universidade para reflexão e convoca a um "paradigma educacional emergente" (MORAES, 2015, p.26), que surge com a necessidade de repensar a educação em favor do humano. É com os estudos da interdisciplinaridade e da transdisciplinaridade que os paradigmas começam a se romper, bem como começamos a perceber a fragmentação do ser (ALVES, 2016).

Deste modo pensar PAII, é pensar que a inclusão se inicia para além dos eixos legais, das intervenções arquietetônicas, é anterior a esse mundo concreto, legal. Não consideramos esses fatores menores é indispensável a regência da lei e as edificações. Mas a verdadeira inclusão está no reconhecimento da existência do outro, esse é lugar impalpável, demarca onde inicia-se genuinamente, "no mundo interno, em um mundo de aceitação de nossas fragilidades e reconhecimento de nossas potencialidades" (ALVES, 2016, p. 38). Inclusão verdadeira no sentido figurado e talvez complexoo e existencial, seja reconhecer a interconexão entre as partes e o todo, é pensar uma educação para todos.

Para Alves (2016, p.39), a inclusão se faz na aceitação do outro como "legítimo outro, bem como na aceitação do outro de si mesmo" como legítimo, único, singular, fio da teia da vida, interligado a tudo e a todos. Como nos diz Morin (2003) na descoberta de nós mesmos, do reconhecimento das nossas fragilidades, insuficiências, carências, teremos a capacidade de perceber que todos têm necessidades e capacidades de compreensão, cooperação e amorosidade. Trata-se de um auto-exame consciente de si mesmo, de forma crítica a respeitar a si, e que permite reconhecer, avaliar e deslocar-se do próprio egoísmo. 
Para pensar o processo inclusivo, é necessário que a palavra do outro seja validada, neutralizando as verdades absolutas, onde os diferentes modos de expressar as verdades da inclusão podem se fundir e tecer outras possibilidades de verdade, que ultrapassa os níveis: da concretude, de realidade e da compreensão humana (ALVES; MURADAS, 2015). Nessa via de repensar o processo inclusivo validando a palavra do outro, garantimos o que Morin (2003) fundamentado nos direitos humanos, chama de mundialização dos direitos do homem, da liberdade, da igualdade, da fraternidade, da equidade e do valor universal da democracia, com vistas ao favorecimento da consciência humana e o reconhecimento da diversidade.

Para Maturana e Varela (1997) a negação do outro gera ódio e desvalida a posição humana, e isso é consequência da falta a solidariedade, enquanto dimensão humana precarizada, todavia ela pode ser capaz de libertar o ser social do humano e recuperar a confiança do humano no humano. Isso, implica pensar pela via da educação em retomar a dimensão da inteligência, solidariedade e cooperação. O resgate ao outro pode ser pensado interventivamente na educação através de uma escola colaborativa, que compartilha e partilha juntos em convivência.

Pensar a diversidade é promover possibilidades inclusivas de convivência onde pessoas com necessidades educacionais especiais podem ensinar e aprender com pessoas sem necessidades especiais. A possibilidade de reconhecer a convivência na diferença pode promover a tolerância em seus diversos aspectos destes constructos da personalidade, como a extroversão e seu contrário, a timidez, até a tolerância religiosa. Assim, pensar a convivência inclusiva está para além das deficiências. Incluir é validar o direito de ser e estar do humano independente de questões, sociais, religiosas, étnicas, econômicas, físicas, etc. Incluir é legitimar a diversidade.

No campo da educação, pensar interventivamente nos aspectos relacionados ao ensino-aprendizagem, implica pensar que diante da pluralidade humana, os métodos de ensino exigem grande esforço para serem singulares. Contudo, é uma fronteira tênue pensar essa 
diversidade metodológica, porque implica justificar que pessoas com síndrome de Down aprendem por um método, e pessoas com autismo por outro, e daí outras categorizações vão sendo criadas. Essas categorizações atendem a uma demanda classificatória massificatória, patológica e não às nuances da singularidade e da subjetividade. Quanto mais diversas forem as modalidades de ensinagem ${ }^{2}$, as estratégias e os cenários, mais serão as diversas possibilidades de aprendizagem (ALVES, 2016). Molta (2006, p. 86) propõe "aprendizagens cooperativas" que permitem que esses alunos se sintam juntos, partilhando relações cognoscentes, humanas, identificatórias.

Alves (2016) aponta que é por meio do diálogo amplo entre os atores envolvidos no processo é que se faz possível desenvolver práticas de aprendizagem integradoras e inclusivas. É um meio para reconhecer e legitimar o outro, único, inserido numa rede de sistêmica. É possibilitar o reconhecimento da singularidade. Para esta autora (ibid, p.43) é desenvolver a consciência, de uma existência sistêmica, já que estamos inseridos em um circulo recursivo composto pela tríade homem, sociedade natureza, numa relação de (co) dependência, onde o homem/mulher se constrói e/ou se destrói mutuamente. Assim, "tudo que se faz a parte, se faz ao todo, e tudo que se faz ao todo se faz a parte".

Nesse círculo recursivo e retroativo, as PAIIs se inserem em todos os espaços: escolas, empresas, espaços virtuais, nas ruas etc., com o intuito de compreender a dimensão humana e autenticar a singularidade. Assim, intervir com as ferramentas da educação na produção de homem/mulher, ensinar a viver a humanamente, e se fazer sujeito implicado com a realidade, individual e coletiva, ser humano implicado com a responsabilidade social de (con)viver.

Pensar na construção de práticas de aprendizagem integradoras e inclusivas é possibilitar uma articulação no percurso da in-

O termo ensinagem é cunhado por Alícia Fernandez na obra A inteligência aprisionada e aqui é utilizado no sentido de que ensinar e aprender são processos resultantes da interação dialética entre aquele/a que ensina e aquele/a que aprende, em movimento de autoria de pensamento. 
tervenção, "como um caminho que se faz ao caminhar" (ALVES, 2016, p. 55) onde frente a diversidade há uma possibilidade em convergir os conhecimentos, como numa bifurcação que possibilita um novo fazer. Numa perspectiva integradora o acolhimento ao outro é um mote imprescindível para a materialização do ser-sendo, do viver-convivendo, da construção da autoria em suas multiplas dimensões. Como afirma Ferreira (2010), o desafio para educação no século XXI é pensar a respeito da questão da multietnicidade, da convivência plural e democrática e da unidade na diversidade.

A escola enquanto lócus de PAII é um lugar de resistência levantada com fins a educação, como a tarefa prática de preparar os indivíduos para a vida social, já que cotidianamente constatamos que "as relações de sociabilidade são de desconfiança, violência e agressão e os cidadãos emergem como 'inimigos potenciais" (FERREIRA, 2010, p. 22). A intervenção em PAII se contrapõe às formas tradicionais e disciplinares de Educação que de tal modo acham-se corroídas. Esse tipo de intervenção possui uma função educativa e não apenas de escolarização. Visa, como aponta Ferreira (2010), construir uma outra visão da escola, dos conteúdos escolares, do papel dos educadores e da relação da escola com a sociedade. Consiste em desenvolver conhecimentos e habilidades, ocupando-se na formação integral do ser humano e terá como missão suprema a formação do sujeito ético.

Pensar na perspectiva de uma educação comprometida com o processo de humanização, é reconstruir o papel formativo da escola. A escola enquanto lugar de pluralidade na sua forma mais complexa de pensar, é um cenário que permite a manifestação vivida dos afetos e esse fenômeno não pode ser minimizado a favor da posição conteudista.

Não é nosso objetivo romantizar de forma fantasiosa a educação, mas sim lançar luz à outras dimensões que não são só cognitivas. Frente as experiencias diárias no campo educacional, sabemos que o afeto influencia diretamente as relações e os processos de aprendizagem, requerendo visões inclusivas e capazes de resgatar a 
dimensão de cuidado necessária ao processo educativo (FERREIRA, 2010, p. 23).

Vale salientar que não consideramos menos importante a dimensão cognitiva, consideramos tão importante quanto a dimensão da afetividade. Nesse aspecto o ambiente escolar é privilegiado para formação dos sujeitos, entretanto, essa formação não deve ser exclusiva à cognição. Se faz necessário reconhecer e possibilitar a expressão dos afetos no ato educativo, na relação com os pares. Deve-se contemplar a afetividade, de forma objetiva, nas atividades propostas, nas relações que são estabelecidas, nos ditos e não ditos que povoam o imaginário escolar.

Pensar em práticas de aprendizagem integradoras e inclusivas implica em promover ações que tentem atingir as diversas dimensões do humano. Destarte, se faz necessário contemplar o sujeito de maneira inteira, promover experiências cognoscentes, cinestésicas, intuitivas, afetivas e criativas. Pensar em práticas de aprendizagem integradora inclusiva significa pensar o humano no social e dentro de si mesmo, implicado com sua própria existência, na partilha e na comunhão com o outro. Significa possibilitar a cada ser humano o habitar e o habitar-se. Construir espaços de convivência e interdependência entre seres e saberes.

Assim, na atualidade onde o conhecimento está pulverizado faz-se necessário recriar a educação, a partir do pensamento complexo e de práticas de aprendizagem integradoras e inclusivas.

\section{Conclusões: inclusão e a tessutura de nós mesmos}

Neste artigo, tivemos como intensão inicial buscar respostas para as questões: Inclusão; qual o caminho? Qual minha bússola? Desta feita, percebemos que os caminhos nos remetem a repensar nossos valores: em perceber que o que importa está para além do fazer, está na essência do ser (ALVES, 2015).

Vimos em Moraes, (2015) que os efeitos do paradigma cartesiano nos mostram que tanto a escola como a universidade pedem uma mudança paradigmática. Deste modo se faz necessário de re- 
pensar a educação em favor do humano, em favor a inclusão, em favor de construir um mundo para todos, um mundo em que todos caíbam (ALVES, 2016).

Assim sendo, pensar as Práticas de Aprendizagem Integradoras, é pensar que a inclusão se inicia para além da legalidade, para além dos paradigmas e barreiras arquietetônicas. Não consideramos esses fatores menores é indispensável a regência da lei e as edificações. Podemos afirmar, a partir das teorías explicitadas e de nosso conviver que a inclusão está no reconhecimento da existencia do "ser, do sujeito em sua singularidade e diversidade. Incluir é criar o lugar de pertencimento, de habitar e habitar-se (ALVES, 2016, p. 38).

Inclusão verdadeira é reconhecer a interconexão Para tal, o caminho ontológico e epistemológico sobre inclusão e complexidade aponta-nos para valores e principios que habitam o "humano e no humano" (MORIN, 2002). Desde seu fazer biológico, ao noss constituir ontólogico e antropológico, somos seres que tanto do autopoiéticos e de amoridade, de cooperação, e de solidariedade (MATURANA, 2001; MATURANA E VARELA, 1997). Pelo olhar de Morin (2002), podemos perceber que somos seres hologramático, dialógicos, recusivos, retroativos, cognocentes, auto-eco-hetero dependentes. Caminhos, fazemo-nos na tessitura comum.

Destarte, percebemos ao final, que atitudes se materializam quando há o desejo de conexão, quando no outro e em nós, há o sentimento de pertença, de ligação, de coesão, conexão. Assim, podemos dizer que, não há vazio que não se preencha quando encontramos o sentido de nossa existência, em nossa pertença Recursivamente nos reconstruímos, co-construimos, construimo.nos junto com o "outro". O outro que se faz nosso espelho e complementar, nossa outra parte, nosso holograma. Somos teia, somos tessitura, somos fios emaranhados tecendo nossa existência, nossa existência.

\section{Referências}

ALVES, M.D.F, PEREIRA FILHO, A.D. Inclusão: um direito à cidadania. Revista Filosofia Capital, Brasília, DF. Edição Especial: Heranças e elementos educacionais V. 12 p. 61-67, 2017. 
ALVES, M. D. F.; MURADAS, M. J. Caminhos da Inclusão e a Inclusão como Caminho. Fortalecendo a Teia da vida In: EDUCERE, III Seminário Internacional de Representações Sociais, Subjetividade e Educação. SIRSSE. Curitiba: PUCPR, 2015. v. 1. p. 15250-15266.

ALVES, M. D. Cenários e estratégias de aprendizagem integradoras: a complexidade e transdisciplinaridade legitimando a diversidade e o "habitar humano". Revista Terceiro Incluído, v.5, n.1, Jan./Jun., 2016, p. 315-338.

ALVES, M. D. De professor a educador. Contribuições da Psicopedagogia: ressignificar os valores e despertar a autoria. $3^{\text {a }}$. Ed. Rio de Janeiro: WAK Editora, 2015 .

ALVES, M. D.; HOLANDA, M. J. Criatividade, espiritualidade e educação: acolhendo a diversidade e favorecendo a inclusão. Revista Filosofia Capital, v. 9, 2014, p. 38-49.

ALVES, M. D.; VIDINHA, M. S. Caminhos metodológicos da teia da diversidade: a pesquisa-ação pelo olhar do pensar complexo e transdisciplinar. In.: CONGRESSO INTERNACIONAL MARISTA DE EDUCAÇÃO, 5 , 2016, Pernambuco, Recife, Olinda. Sentidos, experiências e horizontes. Pernambuco, Recife/Olinda, 2016.

BRASIL. Lei ${ }^{\circ}$ 4.024, de 20 de dezembro de 1961. Fixa as Diretrizes e Bases da Educação Nacional. Brasília, DF: Congresso Nacional, 1961.

BRASIL. Lei $\mathbf{n}^{\circ}$ 5.692, de 11 de agosto de 1971. Fixa Diretrizes e Bases para o ensino de $1^{\circ}$ e $2^{\circ}$ graus e dá outras providências. Brasília, DF: Congresso Nacional, 1971.

BRASIL. Constituição da República Federativa do Brasil. Brasília, DF: Senado Federal, 1988.

Lei $\mathbf{n}^{\mathbf{0}}$ 10.172, de 9 de janeiro de 2001. Aprova o Plano Nacional de Educação e dá outras providências. Brasília, DF: Congresso Nacional, 2001.

BAPTISTA, C. R. Inclusão, cotidiano escolar e políticas públicas: sentidos e perspectivas. In.: SORRI-BRASIL (org.). Ensaios pedagógicos: construindo escolas inclusivas. Brasília: MEC, SEESP, 2005.P. 15-20.

FREUD, S.(1930 [1929]) O mal-estar na civilização. Edição Standard Brasileira das Obras Completas de Sigmund Freud, vol. XXI. Rio de Janeiro: Imago, 1996. 
FERREIRA, A. L.; ACIOLY-RÉGNIER, N. M. Contribuições de Henri. Educar, Curitiba, n. 36, p. 21-38, 2010. Editora UFPR.

FREIRE, Paulo. Pedagogia da esperança: um reencontro com a pedagogia do oprimido. Editora Paz e Terra, 2018.

DEClaraÇÃO DE SALAMANCA. Sobre Princípios, Políticas e Práticas na Área das Necessidades Educativas Especiais. Salamanca-Espanha, 1994.

DECLARAÇÃO MUNDIAL SOBRE EDUCAÇÃO PARA TODOS. Satisfação das necessidades básicas de aprendizagem. Conferência Mundial sobre Educação para Todos, Jomtien, Tailândia: UNESCO, 1990.

DESCARTES, R.Philosophical Letters. Trad. A. Kenny. Oxford: Oxford University Press, 1970.

GUIJARRO, M. R. Inclusão: um desafio para os sistemas educacionais. In.: SORRI-BRASIL (org.). Ensaios pedagógicos: construindo escolas inclusivas. Brasília: MEC, 2005. p. 7-14.

MANTOAN, Maria Tereza Eglér (org.). O desafio das diferenças nas escolas. 4. ed. Petrópolis, RJ: Vozes, 2013.

MATURANA, Humberto. Cognição, ciência e vida cotidiana. Org. e tradução Cristina Magro, Victor Paredes. Belo Horizonte: Ed. UFMG, 2001.

MATURANA, H. VARELA, F. Ontologia da realidade. In. Magro, C. et al. (Orgs.) Belo Horizonte: Ed. UFMG, 1997.

MORIN, E. O método V: A humanidade da humanidade, a identidade humana. Porto Alegre: Sulina, 2002.

MORIN, E. A cabeça bem-feita: repensar a reforma, reformar o pensamento. $21^{\mathrm{a}}$ edição. Rio de Janeiro: Bertrand, 2015.

MORIN, E. O método 1: A natureza da natureza. Porto Alegre: Sulina, 2005.

MORIN, E. Em busca dos fundamentos perdidos. Porto Alegre: Sulina 2003.

MORIN, E. Introdução ao pensamento complexo. Trad. Eliane Lisboa. $3^{\mathrm{a}} \mathrm{ed}$. Porto Alegre: Sulinas, 2007. 
MORAES, Maria Cândida. Transdisciplinaridade, criatividade e educação: Fundamentos ontológicos e epistemológicos/ colaboração de Juan Miguel Batalloso Navas. Campinas, SP: Papirus, 2015.

NICOLESCU, B. O manifesto da transdisciplinaridade. São Paulo: Trion, 2009.

NICOLESCU, B. Fundamentos metodológicos para o estudo transcultural e transreligioso. In: Educação e transdisciplinaridade II. São Paulo: Trion/UNESCO, 2002.

PETRAGLIA, I. C; Edgar Morin: a educação e a complexidade do ser e do saber. Vozes, 2008.

SANTOS, B. S.; CHAUI, M. Direitos humanos, democracia e desenvolvimento. São Paulo: Cortez Editora, 2013.

TEIXEIRA, A.; et al. Manifesto dos pioneiros da educação nova (1932). Revista HISTEDBR On-line, Campinas, n. especial, p.188-204, ago. 2006. 